\title{
Concomitant mechanical complications of true silent inferior myocardial infarction; interventricular septal aneurysm, and ventricular septal rupture mimicking congenital ventricular septal defect (VSD): A case report
}

tahereh davarpasand ${ }^{1}$, reza mohseni badal abadi ${ }^{1}$, mohammad sadeghian ${ }^{1}$, Seyedeh hamide mortazavi $^{1}$, and atefeh lalvand ${ }^{1}$

${ }^{1}$ Tehran University of Medical Sciences

July 3, 2021

\begin{abstract}
This case report demonstrate concurrent of two rare complications of true silent inferior STEMI in the poorly controlled diabetic patient with de-novo heart failure, mimicking congenital VSD. This complication of myocardial infarction often have catastrophic manifestations and the presence of this complications of MI with smooth course is very scarce
\end{abstract}

\section{Hosted file}

Manuscript.pdf available at https://authorea.com/users/423557/articles/528901-concomitantmechanical-complications-of-true-silent-inferior-myocardial-infarction-interventricularseptal-aneurysm-and-ventricular-septal-rupture-mimicking-congenital-ventricular-septaldefect-vsd-a-case-report

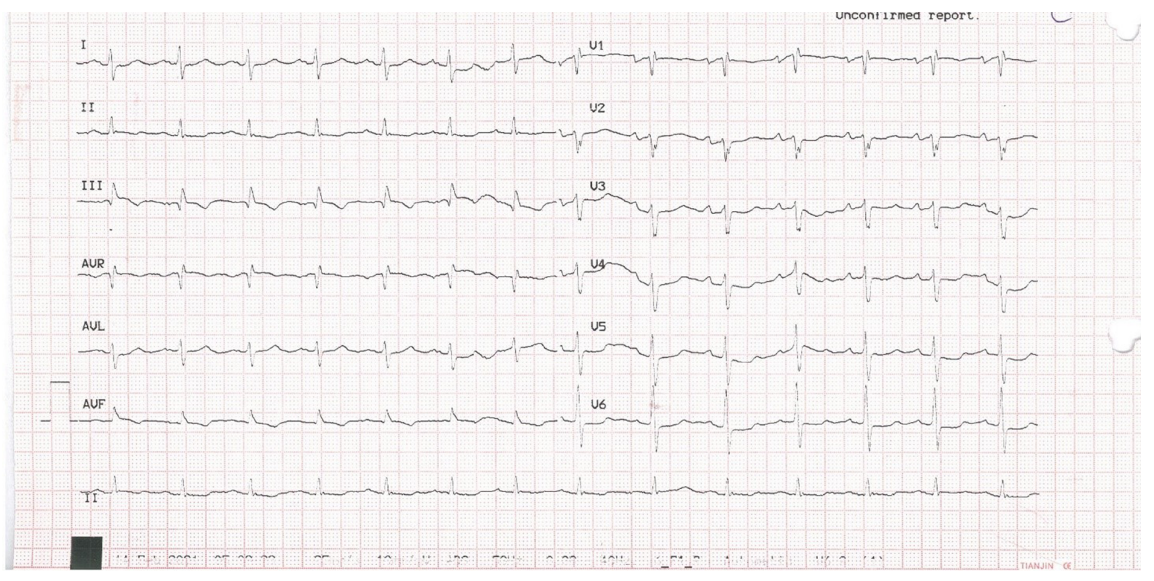



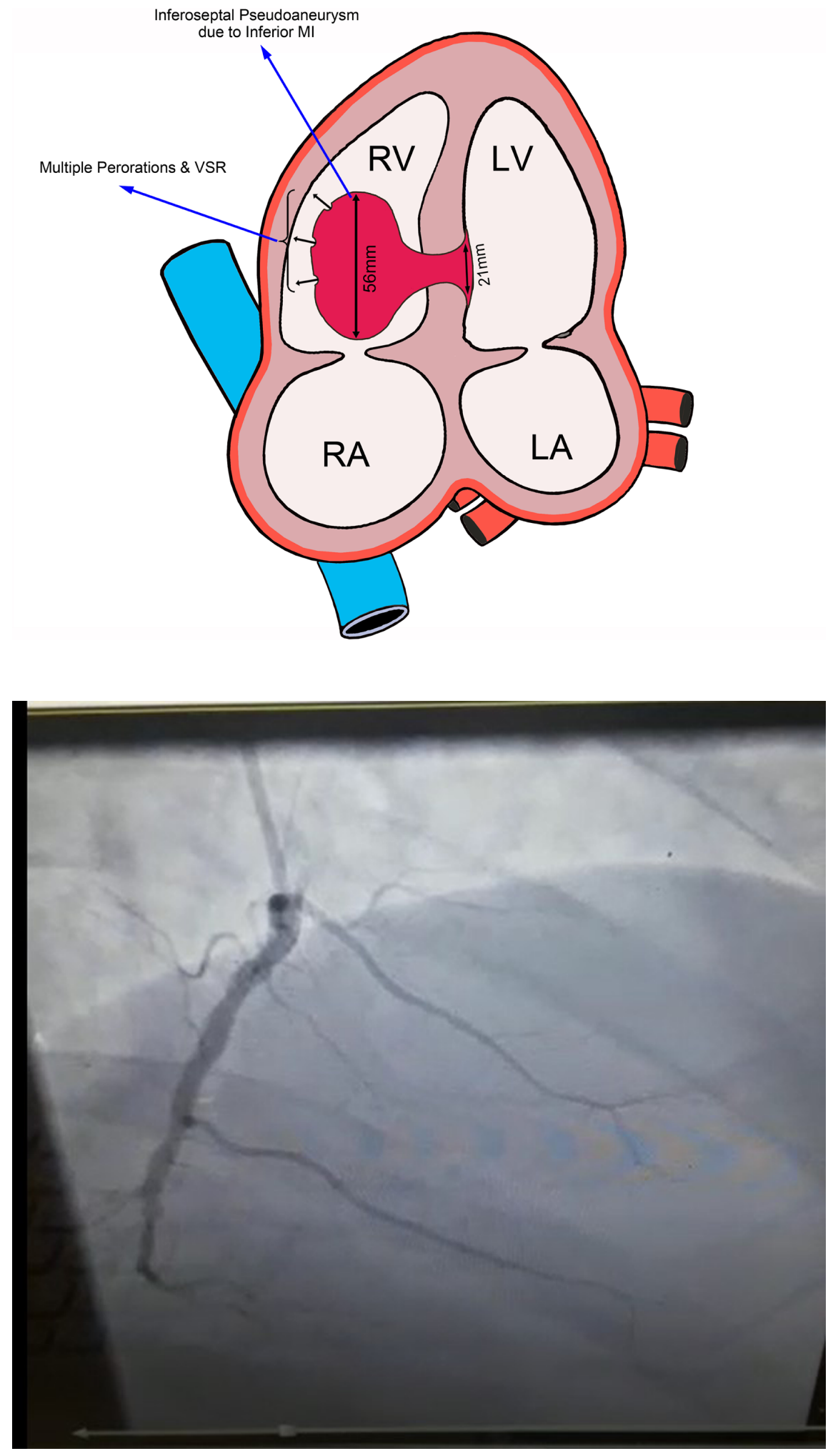

2 


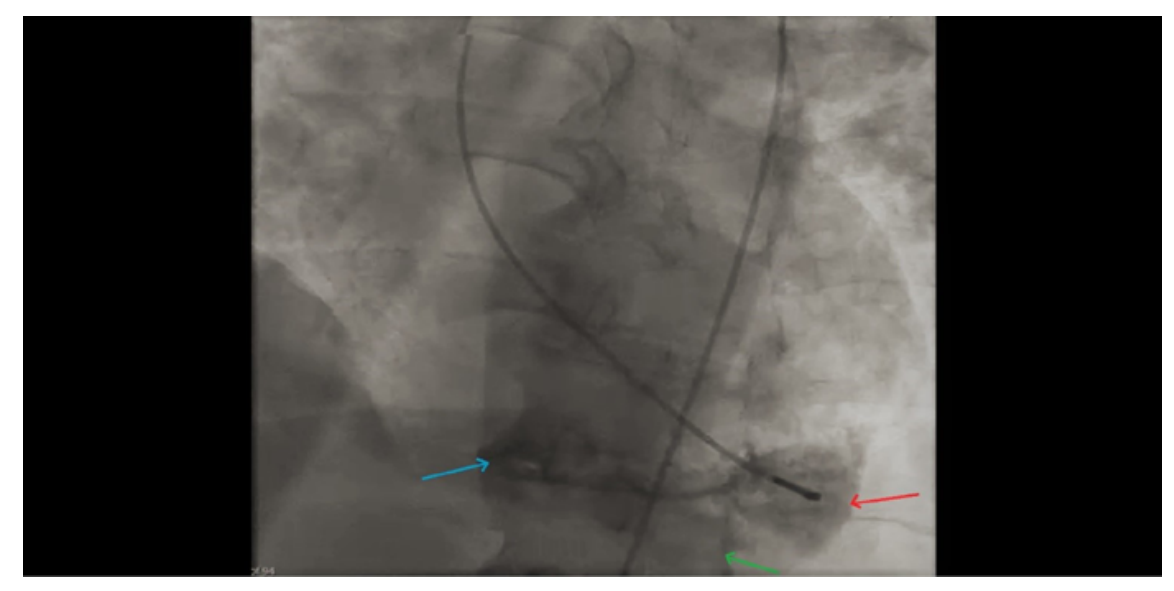

